BMJ Open

Diabetes

Research

\& Care

\section{Peripheral artery disease, lower limb revascularization, and amputation in diabetes patients with and without coronary artery disease: a cohort study from the Western Denmark Heart Registry}

To cite: Olesen KKW, Gyldenkerne C, Thim T, et al. Peripheral artery disease, lower limb revascularization, and amputation in diabetes patients with and without coronary artery disease: a cohort study from the Western Denmark Heart Registry. BMJ Open Diab Res Care 2021;9:e001803. doi:10.1136/ bmjdrc-2020-001803

Supplemental material is published online only. To view, please visit the journal online (http://dx.doi.org/10.1136/ bmjdrc-2020-001803).

Received 1 August 2020 Revised 27 October 2020 Accepted 22 November 2020

Check for updates

(C) Author(s) (or their employer(s)) 2021. Re-use permitted under CC BY-NC. No commercial re-use. See rights and permissions. Published by BMJ.

${ }^{1}$ Department of Cardiology, Aarhus Universitetshospital, Aarhus, Denmark

${ }^{2}$ Department of Clinical Epidemiology, Aarhus University Hospital, Aarhus, Denmark

Correspondence to Dr Kevin Kris Warnakula Olesen; kevole@clin.au.dk

\section{ABSTRACT}

Introduction Patients with diabetes have increased risk of lower limb revascularization and amputation due to higher risk of peripheral artery disease (PAD) and peripheral neuropathy. The additive effect of coronary artery disease $(C A D)$ is less clear. We examined the risk of PAD, lower limb revascularization, and amputation in diabetes and non-diabetes patients with and without CAD in patients examined by coronary angiography (CAG).

Research design and methods We included all patients undergoing CAG between 2003 and 2016 in Western Denmark. Patients with previous CAD, PAD, lower limb revascularization, or amputation were excluded. Patients were stratified by diabetes and CAD status and followed for a maximum of 10 years. Outcomes were PAD, lower limb revascularization, and amputation. We estimated 10-year cumulative incidences and adjusted HRs (aHRs) using patients neither diabetes nor CAD as reference.

Results A total of 118787 patients were included, of whom 41878 (35\%) had neither diabetes nor CAD, 5735 (5\%) had diabetes alone, 59427 (50\%) had CAD alone, and $11747(10 \%)$ had both diabetes and CAD. Median follow-up was 6.9 years. Diabetes patients without CAD had higher risk of PAD $(3.5 \%$, aHR $1.73,95 \% \mathrm{Cl} 1.51$ to 1.97$)$, lower limb revascularization (1.6\%, aHR 1.55 , $95 \% \mathrm{Cl} 1.16$ to 2.05$)$, and lower limb amputation (2.4\%, aHR $5.51,95 \% \mathrm{Cl} 4.09$ to 7.43 ) compared with patients with neither diabetes nor CAD. CAD was associated with 2.5-fold and 1.8-fold higher risk of PAD and amputation, respectively, among patients without diabetes, and associated with 3.9-fold and 9.5-fold higher risk of PAD and lower limb amputation among patients with diabetes.

Conclusions Despite absence of obstructive CAD, patients with diabetes remained at higher risk of PAD, lower limb revascularization, and lower limb amputation. Diabetes was more strongly associated with amputation than CAD, but CAD exacerbated the risks of PAD, revascularization, and amputation in patients with diabetes.

\section{Significance of this study}

What is already known about this subject?

- Patients with diabetes have increased risk of lower limb amputation due to higher risk of peripheral artery disease and peripheral neuropathy. The role of concomitant coronary artery disease (CAD) is unclear.

What are the new findings?

> Patients with diabetes are at higher risk of lower limb amputation despite absence of CAD.

- However, CAD significantly exacerbates amputation risk among patients with diabetes, especially in patient with multivessel CAD.

- Diabetes patients without CAD were more likely to undergo distal amputations, rather than proximal amputations, which were associated with CAD.

How might these results change the focus of research or clinical practice?

- Continued screening and treatment of macrovascular and microvascular disease is necessary in all patients with diabetes to reduce the risk of amputation. However, patients with diabetes and CAD may require additional screening, management, and treatment of peripheral artery disease and microvascular disease to reduce the risk of lower limb amputation. This, however, needs to be explored in a randomized setting.

\section{INTRODUCTION}

Diabetes is associated with a higher risk of atherosclerotic cardiovascular disease including ischemic stroke, coronary artery disease (CAD), and peripheral artery disease (PAD). ${ }^{12}$ Patients with diabetes also have an increased risk of microvascular disease, including peripheral neuropathy, which can 
cause foot ulcers. Poor glycemic control, type of diabetes, previous lower limb revascularization, hypertension, and high level of comorbidity are all associated with increased risk of amputation in patients with diabetes. ${ }^{3}$ Atherosclerosis in one vascular bed is often associated with presence or development of atherosclerosis in other vascular beds. ${ }^{4}$ Considering the combination of increased atherothrombotic risk and the risk of microvascular disease, patients with diabetes have a higher risk of lower limb ischemia and amputation. The absence of obstructive $\mathrm{CAD}$ is associated with a low risk of myocardial infarction and an intermediate risk of ischemic stroke in patients with diabetes. ${ }^{5-7}$ However, does the absence of obstructive CAD ensure a low risk of PAD, lower limb revascularization, and amputation in patients with diabetes?

We conducted a cohort study of diabetes and nondiabetes patients with and without obstructive CAD to estimate the risk of PAD, lower limb revascularization, and lower limb amputation. We hypothesized that the absence of obstructive CAD by coronary angiography (CAG) would be associated with low risks of PAD, lower limb revascularization, and lower limb amputation in both diabetes and non-diabetes patients.

\section{METHODS}

\section{Setting}

All Danish residents are assigned a unique 10-digit identifier at birth or immigration. This identifier is used throughout every national and regional registry, thus allowing accurate cross-linkage of data between registries. The Civil Registration System contains information on vital status of every resident in Denmark, ${ }^{8}$ hereby reducing loss to follow-up $(<0.3 \%) \cdot{ }^{9}$ The Danish National Patients Registry records every discharge diagnoses for in-hospital admission and visits to outpatient clinics in national Danish healthcare system. ${ }^{10}$ The Danish National Prescription Registry contains information on every dispensed prescription from a Danish pharmacy since 1994. ${ }^{11}$ The Western Denmark Heart Registry has registered every cardiac procedure in Western Denmark since 1999, and it contains detailed patient-related and procedural information that includes the presence and extent of CAD. ${ }^{12}$

\section{Patient selection}

We included all patients examined by CAG from 1 January 2003 to 31 December 2016 (figure 1). We excluded patients aged $<18$ years and patients with previous history of myocardial infarction (MI), percutaneous coronary intervention, or coronary artery bypass grafting (CABG) prior to CAG date to identify patients with a first-time diagnosis of CAD. We also excluded patients diagnosed with PAD, previous lower revascularization, or amputation before start of follow-up. Patients with missing CAD status were not included, as well as patients classified as 'no CAD' but were revascularized within 30 days of CAG.
Lastly, patients who either died or emigrated $<30$ days after CAG were excluded.

\section{Diabetes}

Diabetes was defined as at least one of the following: (1) dietary treatment for diabetes, oral diabetes treatment, or receiving insulin treatment ( \pm oral diabetes treatment) recorded in the Western Denmark Heart Registry, (2) a previous diabetes diagnosis registered in the Danish National Patient Registry before start of follow-up, or (3) redeeming $\geq 1$ prescription(s) of insulin or non-insulin diabetes medication 6 months before or 30 days after CAG.

\section{Coronary artery disease}

CAD was defined as $\geq 1$ obstructive stenoses ( $\geq 50 \%$ lumen narrowing) or non-obstructive stenosis in $\geq 2$ coronary vessels by CAG according to the Western Denmark Heart Registry. ${ }^{12}$

\section{Outcomes}

PAD was defined as a primary or secondary discharge diagnoses of PAD during hospitalization or visit to outpatient clinic (online supplemental table S1). Lower limb revascularization was defined as thrombectomy, percutaneous transluminal angioplasty, or arterial bypass surgery distal from the infrarenal aorta. Lower limb amputation was defined as an amputation from hip down. ${ }^{10}$ The level of the amputation was evaluated as separate outcomes (hip/femur amputation, knee/lower leg amputation, and ankle/foot/toe amputation).

\section{Statistical analysis}

Follow-up started 30 days after CAG to allow for any CAGrelated changes in comorbidities and medications to be registered. Follow-up continued until outcome, emigration, death, end of follow-up (31 December 2018) with a maximum of 10 years of follow-up. Events occurring more than 10 years after start of follow-up were censored. Event rates per 100 person-years were estimated. The 10-year cumulative incidence proportions accounting for the competing risk of all-cause death were calculated. Crude and adjusted HRs (aHRs) were estimated using Cox proportional regression analysis and non-diabetes patients without CAD as reference. The central assumption of proportional hazards was evaluated by log-log plots and found to be satisfied. HR were adjusted for age, sex, hypertension, microvascular disease, active smoking, categorized body mass index $\left(<18.5 \mathrm{~kg} / \mathrm{m}^{2}, 18.5-24.9\right.$ $\left.\mathrm{kg} / \mathrm{m}^{2}, 25-29.9 \mathrm{~kg} / \mathrm{m}^{2}, \geq 30 \mathrm{~kg} / \mathrm{m}^{2}\right)$, oral anticoagulant treatment (vitamin $\mathrm{K}$ antagonists or direct oral anticoagulants), antiplatelet treatment (aspirin and/or adenosine diphosphate (ADP) inhibitors), and statin treatment. A total of $19.3 \%$ of patients had missing data of either smoking (9.9\%) and/or body mass index (14.4\%). Missing data were handled through multiple imputation using chained equations, imputing 20 datasets. ${ }^{1314}$ 
4 patients $<18$ years

25,292 with previous MI, $\mathrm{PCl}$, or $\mathrm{CABG}$

6,590 patients with $P A D$, lower limb revascularization or amputation

463 patients with missing CAD status

308 patients registered as " 0 vessel disease" but were revascularized within 30 days after CAG

2,742 subjects who died or emigrated $<30$ days after inclusion

\section{4,186 CAG patients}

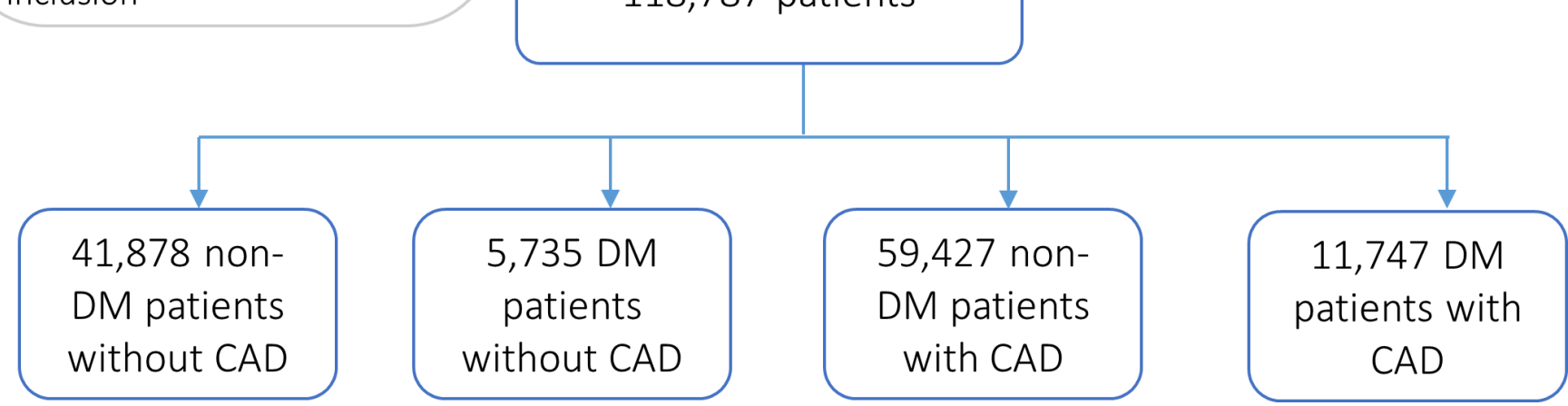

Figure 1 Patient selection. CAD, coronary artery disease; CABG, coronary artery bypass grafting; CAG, coronary angiography; DM, diabetes; MI, myocardial infarction; PAD, peripheral artery disease; PCl, percutaneous coronary intervention.

\section{Diabetes subgroup analysis}

We performed stratified analysis of patients with diabetes by: (1) extent of CAD (0 vessel disease (VD), $1 \mathrm{VD}, 2 \mathrm{VD}$, $3 \mathrm{VD}$, and diffuse VD), (2) type of diabetes treatment, and (3) duration of diabetes ( $0-4$ years, 5-9 years, and $\geq 10$ years). We tested for trend between extent of CAD and each outcomes in patients with diabetes.

\section{Amputation distribution}

We counted the distribution of type of amputation (hip/ femur, knee/lower leg, and ankle/foot/toe), and tested the hypothesis of no difference in distribution of type of amputation using Pearson's $\chi^{2}$ test.

\section{RESULTS}

We included 118787 patients, of whom 41878 (35\%) had neither diabetes nor CAD, 5735 (5\%) had diabetes alone, 59427 (50\%) had CAD alone, and 11747 (10\%) had both diabetes and CAD (figure 1). Median follow-up was 6.9 years (IQR 4.0-10.0).

Regardless of presence or absence of diabetes, patients with CAD were older, more often men, and more often treated with antiplatelet agents and statin (table 1 and online supplemental table S2).

Regardless of CAD, patients with diabetes more often had hypertension, heart failure, previous ischemic stroke, and microvascular disease. Type of diabetes treatment was overall similar between diabetes patients with and without CAD. However, insulin and sulfonylureas were used more frequently among diabetes patients with CAD.

Compared with patients with neither diabetes nor $\mathrm{CAD}$, the risk of PAD and lower limb revascularization was highest in patients who had both diabetes and CAD, followed by patients with CAD alone and patients with diabetes alone (table 2). 
Table 1 Baseline characteristics in patients with and without diabetes by coronary artery status

\begin{tabular}{|c|c|c|c|c|c|c|c|c|}
\hline & \multicolumn{2}{|c|}{$\begin{array}{l}\text { No DM, no CAD } \\
(\mathrm{n}=\mathbf{4 1} 878)\end{array}$} & \multicolumn{2}{|c|}{$\begin{array}{l}\text { DM, no CAD } \\
(n=5735)\end{array}$} & \multicolumn{2}{|c|}{$\begin{array}{l}\text { No DM, CAD } \\
(n=59427)\end{array}$} & \multicolumn{2}{|c|}{$\begin{array}{l}\text { DM, CAD } \\
(n=11747)\end{array}$} \\
\hline & $\mathbf{N}$ & $\%$ & $\mathbf{N}$ & $\%$ & $\mathbf{N}$ & $\%$ & $\mathbf{N}$ & $\%$ \\
\hline Median age (IQR) & \multicolumn{2}{|c|}{$\begin{array}{l}61 \text { years } \\
(52-69)\end{array}$} & \multicolumn{2}{|c|}{62 years $(53-70)$} & \multicolumn{2}{|c|}{$\begin{array}{l}66 \text { years } \\
(58-74)\end{array}$} & \multicolumn{2}{|c|}{$67(59-74)$} \\
\hline Female & 20873 & 49.8 & 2777 & 48.4 & 17810 & 30.0 & 3522 & 30.0 \\
\hline Active smoker ${ }^{\star}$ & 8867 & 21.2 & 1080 & 18.8 & 18215 & 30.7 & 2906 & 24.7 \\
\hline Mean body mass index ${ }^{*}( \pm \mathrm{SD})$ & \multicolumn{2}{|c|}{$26.9 \mathrm{~kg} / \mathrm{m}^{2} \pm 5.1$} & \multicolumn{2}{|c|}{$30.8 \mathrm{~kg} / \mathrm{m}^{2} \pm 6.5$} & \multicolumn{2}{|c|}{$26.8 \mathrm{~kg} / \mathrm{m}^{2} \pm 4.4$} & \multicolumn{2}{|c|}{$29.4 \mathrm{~kg} / \mathrm{m}^{2} \pm 5.3$} \\
\hline Mean eGFR ${ }^{\star}( \pm S D)$ & \multicolumn{2}{|c|}{$\begin{array}{l}89 \mathrm{~mL} / \mathrm{min} \\
(25.6)\end{array}$} & \multicolumn{2}{|c|}{$\begin{array}{l}92 \mathrm{~mL} / \mathrm{min} \\
(32.2)\end{array}$} & \multicolumn{2}{|c|}{$\begin{array}{l}86 \mathrm{~mL} / \mathrm{min} \\
(25.1)\end{array}$} & \multicolumn{2}{|c|}{$\begin{array}{l}86 \mathrm{~mL} / \mathrm{min} \\
(30.2)\end{array}$} \\
\hline Mean systolic $\mathrm{BP}^{*}( \pm \mathrm{SD})$ & \multicolumn{2}{|c|}{137 mmHg (22) } & \multicolumn{2}{|c|}{$140 \mathrm{mmHg}(22)$} & \multicolumn{2}{|c|}{$139 \mathrm{mmHg}(23)$} & \multicolumn{2}{|c|}{$141 \mathrm{mmHg}(23)$} \\
\hline Mean diastolic $\mathrm{BP}^{*}( \pm \mathrm{SD})$ & \multicolumn{2}{|c|}{$78 \mathrm{mmHg}(13)$} & \multicolumn{2}{|c|}{$78 \mathrm{mmHg}(13)$} & \multicolumn{2}{|c|}{$78 \mathrm{mmHg}(13)$} & \multicolumn{2}{|c|}{77 mmHg (13) } \\
\hline Median DM treatment duration, (IQR) & & & \multicolumn{2}{|c|}{$\begin{array}{l}4.0 \text { years } \\
(0.5-9.4)\end{array}$} & & & \multicolumn{2}{|c|}{$\begin{array}{l}4.8 \text { year } \\
(0.6-10.7)\end{array}$} \\
\hline \multicolumn{9}{|l|}{ Cardiovascular disease } \\
\hline Hypertension & 20157 & 48.1 & 4450 & 77.6 & 31761 & 53.4 & 9274 & 78.9 \\
\hline Heart failure & 6246 & 14.9 & 1113 & 19.4 & 9136 & 15.4 & 2441 & 20.8 \\
\hline Ischemic stroke & 594 & 1.4 & 200 & 3.5 & 1190 & 2.0 & 501 & 4.3 \\
\hline Transient ischemic attack & 966 & 2.3 & 137 & 2.4 & 1419 & 2.4 & 382 & 3.3 \\
\hline Carotid stenosis & 30 & 0.1 & 4 & 0.1 & 122 & 0.2 & 40 & 0.3 \\
\hline Atrial fibrillation & 6588 & 15.7 & 1043 & 18.2 & 7048 & 11.9 & 1731 & 14.7 \\
\hline Nephropathy & 49 & 0.1 & 376 & 6.6 & 69 & 0.1 & 825 & 7.0 \\
\hline Retinopathy & 31 & 0.1 & 808 & 14.1 & 30 & 0.1 & 1810 & 15.4 \\
\hline Peripheral neuropathy & 81 & 0.2 & 275 & 4.8 & 126 & 0.2 & 643 & 5.5 \\
\hline Comedication & & & & & & & & \\
\hline Aspirin & 21223 & 50.7 & 3553 & 62.0 & 50368 & 84.8 & 9838 & 83.7 \\
\hline ADP inhibitor & 2289 & 5.5 & 320 & 5.6 & 34370 & 57.8 & 5676 & 48.3 \\
\hline Vitamin $\mathrm{K}$ antagonist & 5638 & 13.2 & 882 & 15.4 & 5260 & 8.9 & 1388 & 11.8 \\
\hline Direct oral anticoagulants & 1030 & 2.5 & 182 & 3.2 & 1207 & 2.0 & 288 & 2.5 \\
\hline Statin & 17543 & 41.9 & 4149 & 72.3 & 51122 & 86.0 & 10302 & 87.7 \\
\hline Insulin & 0 & 0.0 & 1580 & 27.6 & 0 & 0.0 & 3570 & 30.4 \\
\hline Non-insulin & 0 & 0.0 & 3672 & 64.0 & 0 & 0.0 & 7696 & 65.5 \\
\hline Metformin & & & 3167 & 55.2 & & & 6480 & 55.2 \\
\hline Sulfonylureas & & & 1127 & 19.7 & & & 2769 & 23.6 \\
\hline DPP-4 inhibitor & & & 344 & 6.0 & & & 681 & 5.8 \\
\hline GLP-1 analogs & & & 243 & 4.2 & & & 435 & 3.7 \\
\hline SGLT-2 inhibitors & & & 29 & 0.5 & & & 73 & 0.6 \\
\hline Glitazones & & & 42 & 0.7 & & & 100 & 0.9 \\
\hline Repaglinide & & & 22 & 0.4 & & & 44 & 0.4 \\
\hline Acarbose & & & 9 & 0.2 & & & 28 & 0.2 \\
\hline
\end{tabular}

*Missing values: smoking (9.9\%); BMI (14.3\%), eGFR (26.4\%), and blood pressure (13.3\%).

ADP, adenosine diphosphate; BMI, body mass index; BP, blood pressure; CAD, coronary artery disease; DM, diabetes mellitus; DPP-4, dipeptidyl peptidase-4; eGFR, estimated glomerular filtration rate; GLP-1, glucagon like peptide-1; SGLT-2, sodium-glucose cotransporter-2.

Diabetes alone patients had a lower risk of PAD compared with $\mathrm{CAD}$ alone patients (figure 2). However, PAD risk did seem to more progressively increase during follow-up among diabetes alone patients reaching a comparable 10-year risk as patients with $\mathrm{CAD}$ alone (diabetes alone: $6.9 \%$ vs $\mathrm{CAD}$ alone: $7.9 \%$ ). Patients with both diabetes and CAD had an almost 10-fold increased risk of lower limb amputation when compared with patients with neither diabetes nor CAD (3.8\% vs $0.3 \%$, aHR $9.49,95 \%$ CI 7.27 to 12.39$)$. Of note, diabetes alone 
Table 2 Number events, event rates and incidence rate ratios by diabetes status and CAD status

\begin{tabular}{|c|c|c|c|c|c|}
\hline & Events & $\begin{array}{l}\text { Events per } 100 \\
\text { person years } \\
(95 \% \mathrm{Cl})\end{array}$ & $\begin{array}{l}\text { 10-year cumulative } \\
\text { incidence }{ }^{*}(95 \% \mathrm{CI})\end{array}$ & $\begin{array}{l}\text { Unadjusted HR } \\
(95 \% \mathrm{Cl})\end{array}$ & $\begin{array}{l}\text { Adjusted HR† } \\
(95 \% \mathrm{Cl})\end{array}$ \\
\hline \multicolumn{6}{|c|}{ Peripheral artery disease } \\
\hline -DM -CAD & 1170 & 0.40 (0.38 to 0.43$)$ & $3.53 \%$ (3.32 to 4.74$)$ & 1 & 1 \\
\hline$+\mathrm{DM}-\mathrm{CAD}$ & 293 & 0.81 (0.73 to 0.91 ) & $6.89 \%(6.11$ to 7.73$)$ & 1.98 (1.74 to 2.25$)$ & 1.73 (1.51 to 1.97$)$ \\
\hline$-\mathrm{DM}+\mathrm{CAD}$ & 3759 & 1.02 (0.99 to 1.05$)$ & $7.90 \%(7.65$ to 8.16$)$ & 2.48 (2.32 to 2.65 ) & 2.20 (2.04 to 2.37 ) \\
\hline +DM +CAD & 1354 & 2.10 (1.99 to 2.22 ) & $14.56 \%(13.80$ to 15.34$)$ & 5.00 (4.63 to 5.41$)$ & 3.90 (3.55 to 4.28$)$ \\
\hline \multicolumn{6}{|c|}{ Lower limb revascularization } \\
\hline -DM -CAD & 289 & 0.10 (0.09 to 0.11$)$ & $0.89 \%(0.79$ to 1.00$)$ & 1 & 1 \\
\hline$+\mathrm{DM}-\mathrm{CAD}$ & 63 & 0.17 (0.13 to 0.22$)$ & $1.56 \%$ (1.19 to 2.02$)$ & 1.73 (1.31 to 2.27 ) & 1.55 (1.16 to 2.05 ) \\
\hline$-D M+C A D$ & 1090 & 0.29 (0.27 to 0.30$)$ & $2.39 \%$ (2.24 to 2.54$)$ & 2.89 (2.54 to 3.29 ) & 2.51 (2.17 to 2.91 ) \\
\hline$+\mathrm{DM}+\mathrm{CAD}$ & 399 & 0.59 (0.53 to 0.65$)$ & $4.48 \%$ (4.04 to 4.96$)$ & 5.88 (5.05 to 6.84$)$ & 4.61 (3.85 to 5.52 ) \\
\hline \multicolumn{6}{|c|}{ Lower limb amputation } \\
\hline -DM -CAD & 104 & 0.04 (0.03 to 0.04$)$ & $0.34 \%(0.28$ to 0.41$)$ & 1 & 1 \\
\hline$+\mathrm{DM}-\mathrm{CAD}$ & 100 & 0.27 (0.22 to 0.33$)$ & $2.42 \%$ (1.96 to 3.95$)$ & 7.77 (5.91 to 10.23) & 5.51 (4.09 to 7.43 ) \\
\hline$-\mathrm{DM}+\mathrm{CAD}$ & 248 & 0.06 (0.06 to 0.07$)$ & $0.59 \%(0.52$ to 0.67$)$ & 1.84 (1.46 to 2.31$)$ & 2.02 (1.57 to 2.60$)$ \\
\hline$+\mathrm{DM}+\mathrm{CAD}$ & 330 & 0.48 (0.43 to 0.54$)$ & $3.81 \%(3.40$ to 4.25$)$ & 13.86 (11.12 to 17.28$)$ & 9.49 (7.27 to 12.39$)$ \\
\hline \multicolumn{6}{|c|}{ Hip/femur amputation } \\
\hline -DM -CAD & 45 & 0.02 (0.01 to 0.02$)$ & & 1 & 1 \\
\hline$+\mathrm{DM}-\mathrm{CAD}$ & 24 & 0.06 (0.04 to 0.10$)$ & & 4.30 (2.62 to 7.06$)$ & 3.31 (1.95 to 5.61 ) \\
\hline$-\mathrm{DM}+\mathrm{CAD}$ & 148 & 0.04 (0.03 to 0.05$)$ & & 2.54 (1.82 to 3.55$)$ & 2.62 (1.81 to 2.79$)$ \\
\hline$+\mathrm{DM}+\mathrm{CAD}$ & 108 & 0.16 (0.13 to 0.19$)$ & & 10.46 (7.39 to 14.82$)$ & 7.41 (4.87 to 11.28$)$ \\
\hline \multicolumn{6}{|c|}{ Knee/lower leg amputation } \\
\hline -DM -CAD & 36 & 0.01 (0.01 to 0.02$)$ & & 1 & 1 \\
\hline +DM -CAD & 37 & 0.10 (0.07 to 0.14$)$ & & 8.26 (5.22 to 13.07) & 5.19 (3.13 to 8.62$)$ \\
\hline$-\mathrm{DM}+\mathrm{CAD}$ & 74 & 0.02 (0.02 to 0.02$)$ & & 1.58 (1.06 to 2.36$)$ & 1.76 (1.14 to 2.74$)$ \\
\hline$+\mathrm{DM}+\mathrm{CAD}$ & 123 & 0.18 (0.15 to 0.21$)$ & & 14.76 (10.18 to 21.41$)$ & 9.00 (5.69 to 14.23$)$ \\
\hline \multicolumn{6}{|c|}{ Ankle/foot/toe amputation } \\
\hline -DM -CAD & 38 & 0.01 (0.01 to 0.02 ) & & 1 & 1 \\
\hline$+\mathrm{DM}-\mathrm{CAD}$ & 68 & 0.18 (0.15 to 0.23$)$ & & 14.48 (9.73 to 21.53$)$ & 10.20 (6.64 to 15.67$)$ \\
\hline$-D M+C A D$ & 74 & 0.02 (0.02 to 0.02$)$ & & 1.50 (1.02 to 2.22$)$ & 1.85 (1.21 to 2.82$)$ \\
\hline +DM +CAD & 199 & $0.29(0.25$ to 0.33$)$ & & 22.84 (16.14 to 32.34$)$ & 16.67 (11.08 to 25.07$)$ \\
\hline
\end{tabular}

*10-year cumulative incidence proportion accounting for the competing risk of death.

†Adjusted for age, sex, hypertension, microvascular disease, active smoking (imputed), body mass index (imputed), oral anticoagulant treatment, antiplatelet treatment, and statin treatment.

$\mathrm{CAD}$, coronary artery disease; DM, diabetes mellitus.

(2.4\%, aHR 5.51, $95 \%$ CI 4.09 to 7.43$)$ was also associated with an increased risk of lower limb amputation, which was much higher than for patients with CAD alone $(0.6 \%$, aHR $2.02,95 \%$ CI 1.57 to 2.60 ) compared with patients with neither diabetes nor CAD. Risks of PAD, lower limb revascularization, and amputation increased by extent of $\mathrm{CAD}$ in patients with diabetes $\left(\mathrm{p}_{\text {trend }}<0.0001\right.$, figure 3 , online supplemental table S3). Insulin-treated patients with had the highest risks of PAD, revascularization, and amputation (figure 3, online supplemental table S4). Duration of diabetes was also associated risk of PAD and amputation but not revascularization (figure 3, online supplemental table S5). Diabetes patients without CAD more often had distal lower limb amputations (ankle/ foot/toe), while non-diabetes patients with CAD more often underwent proximal amputations (hip/femur) (online supplemental figure S1). The distributions of type of amputation differed significantly $(\mathrm{p}<0.001)$.

\section{DISCUSSION}

The main findings of the study were that diabetes still infers an increased risk of PAD and lower limb amputation despite the absence of obstructive CAD. Diabetes was 

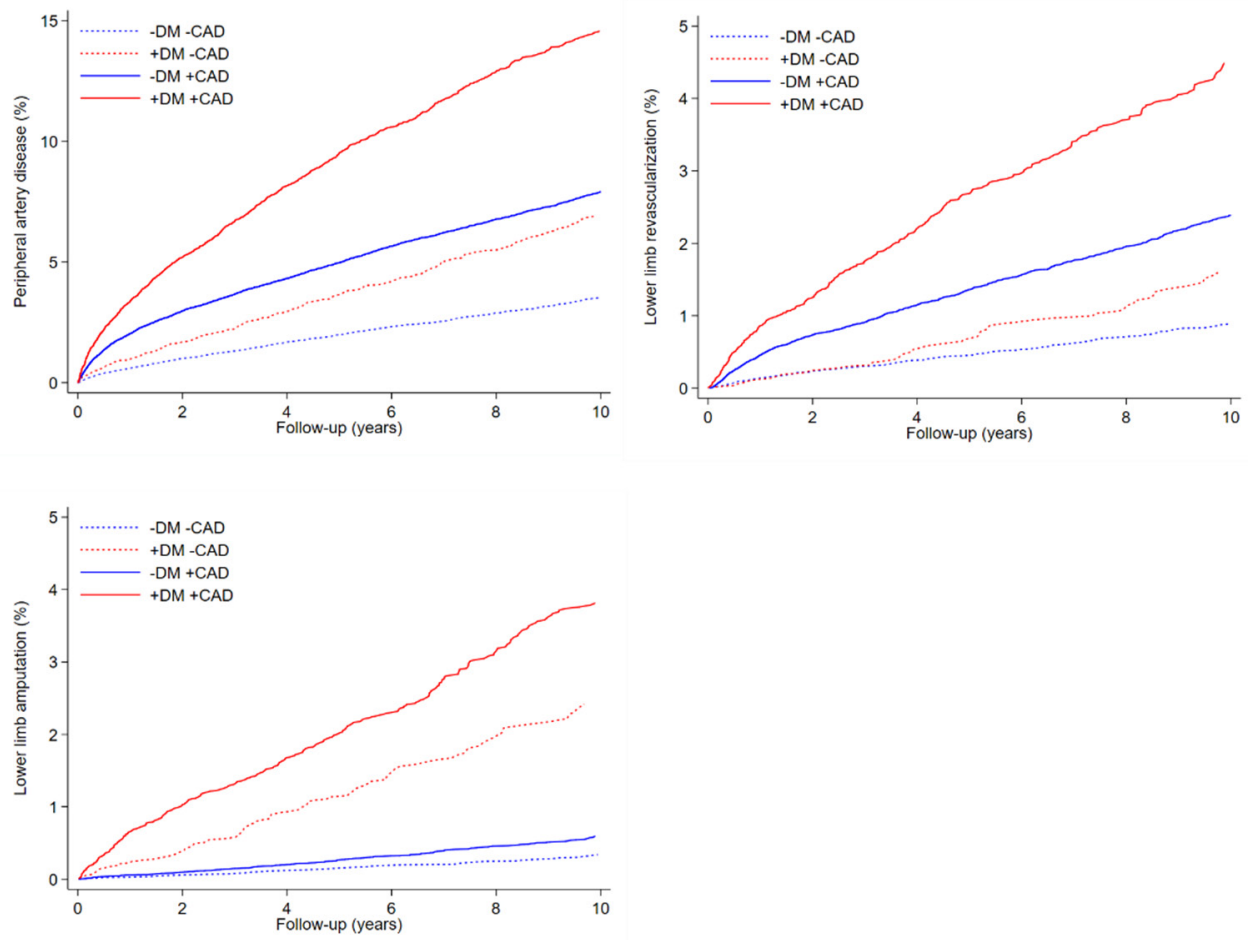

Figure 2 Ten-year cumulative incidence of peripheral artery disease, lower limb revascularization, and lower limb amputation by diabetes and coronary status. CAD, coronary artery disease; DM, diabetes.

associated with a higher risk of lower limb amputation compared with CAD, but the level of amputation differed between the two exposures. Furthermore, CAD was associated with an incremental risk of PAD and amputation among patients with diabetes. Diabetes patients with obstructive multivessel CAD, receiving insulin treatment, or with a long duration of diabetes had the highest risk. Although CAD alone patients had higher risk of PAD and lower limb revascularization than those with diabetes alone, diabetes alone patients remained at much higher risk of lower limb amputation than those with CAD alone. Hence, in patients with diabetes, the absence of CAD reduced the risk of lower limb amputation from a 9.5 -fold increase to a 5.5 -fold increase but did not by any means eliminate their highly elevated risk. Among Danish patients with a high prevalence of lipid-lowering
PAD

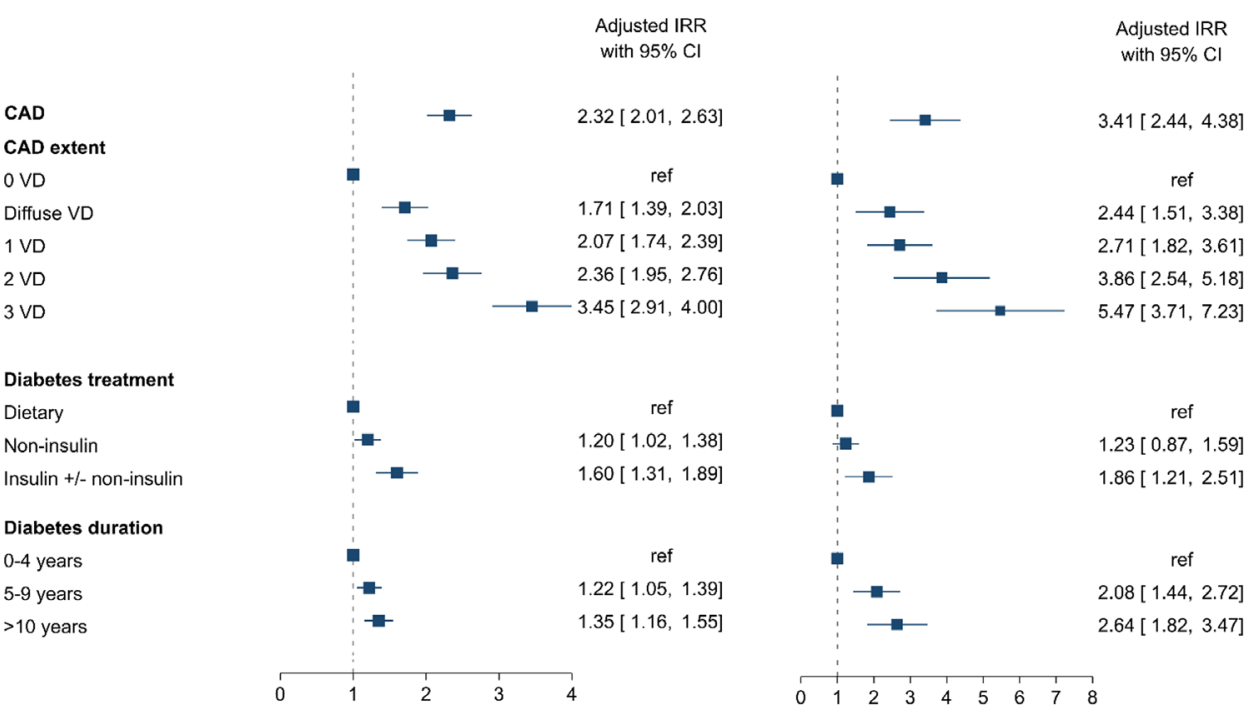

Amputation

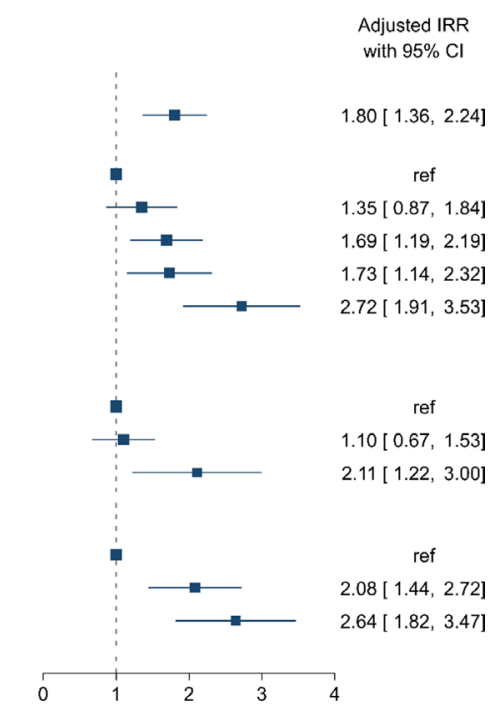

Figure 3 Risk of peripheral artery disease, lower limb revascularization, and lower limb amputation in diabetes patient by presence and extent of CAD, diabetes treatment, and duration of diabetes. CAD, coronary artery disease; IRR, incidence rate ratio; PAD, peripheral artery disease; VD, vessel disease. 
and antithrombotic treatment, MI risk in diabetes alone patients is low and comparable with patients with neither diabetes nor $\mathrm{CAD}$, while their risk of ischemic stroke was higher. ${ }^{5715}$ Hence, the absence of CAD by CAG ensures a sustained low risk of MI in patients with diabetes but does not protect from other cardiovascular outcomes including ischemic stroke, PAD, and lower limb amputation. Although this may not be generalizable to countries outside Denmark, this nevertheless emphasizes the need for continued monitoring and treatment of macrovascular and microvascular disease in patients with diabetes, in particular diabetes patients with CAD.

Patients with diabetes had higher prevalence of microvascular disease, irrespective of CAD status. Patients with diabetes often develop microvascular complications causing visual impairment, loss of sensory function, kidney failure and so on. ${ }^{16-18}$ Foot ulcers and amputations are also more frequent among patients with diabetes due to a combination of PAD and peripheral neuropathy. ${ }^{1}$ Reduced pain sensitivity may postpone PAD diagnosis in diabetes patients with polyneuropathy. Furthermore, microvascular disease increases the risk of amputation independently of PAD. ${ }^{19}$ Diabetes patients with peripheral microvascular disease have a higher risk of disseminated macrovascular atherosclerotic disease in multiple organs, including $\mathrm{CAD}, \mathrm{PAD}$, and cerebrovascular disease..$^{20}$ Moreover, diabetes is associated with coronary microvascular disease and subsequent risk of adverse ischemic events. ${ }^{21}$ Screening for microvascular disease is a central part of diabetes management, and foot evaluations are recommended to prevent development of ulcers and amputation..$^{22}$ We found that diabetes was associated with a higher prevalence of microvascular disease, which may both reflect a true higher prevalence as well as surveillance bias caused by routine screening of patients with diabetes in the primary sector. This could, in part, explain the higher amputation risk among patients with diabetes. Diabetes alone was primarily associated with distal amputations, whereas CAD alone was associated with proximal amputations. However, even when adjusting for diagnosed microvascular disease, diabetes alone patients still had higher risk of amputation than CAD alone patients.

CAD was associated with an increased risk of developing PAD and having lower limb revascularization. The Action in Diabetes and Vascular Disease: Preterax and Diamicron MR Controlled Evaluation (ADVANCE) trial found that microvascular disease increased the risk of PAD and amputation in patients with type 2 diabetes, while macrovascular disease (previous coronary heart disease or cerebrovascular disease) did not affect the risk of PAD or amputation. ${ }^{23} \mathrm{~A}$ recent Danish cohort stratified patients with and without diabetes by extent of CAD by angiography ( $\mathrm{n}=116491)$, and similarly found that $\mathrm{CAD}$ extent was associated with an increased risk of PAD in patients with diabetes 5 years after CAG, with significant interaction between diabetes and CAD extent $\left(\mathrm{p}_{\text {interaction }}=0.042\right) .{ }^{24}$ Researchers did not examine lower limb revascularization or amputation. As a confirmation and extension of the Danish angiographic cohort, ${ }^{24}$ we report that the presence of CAD more than doubles the risk of PAD, lower limb revascularization, and lower limb amputation. Our cohort consists of routine clinical care patients undergoing CAG contrary to the ADVANCE trial that included a more selective group of patients with type 2 diabetes. Furthermore, macrovascular disease was associated with revascularization for PAD (HR 1.75, 95\% CI 1.13 to 2.73 ) in the ADVANCE trial too.

More than 8 in 10 patients with CAD received treatment with aspirin. The remaining were almost all treated with oral anticoagulants. Similarly, almost 9 in 10 patients with CAD were in statin treatment. Antiplatelet monotherapy and statin treatment are recommended in patients with symptomatic PAD. ${ }^{25}$ Oral anticoagulants are currently not recommended in management of PAD. However, more recently low dose of rivaroxaban in combination with aspirin has been found to reduce cardiovascular risk, including major amputation (HR 0.30, 95\% CI 0.11 to 0.80 ), in patients with stable CAD or PAD. ${ }^{26} 27$ Moreover, additional antithrombotic treatment, including low-dose rivaroxaban, should be considered in chronic coronary syndrome patients with diabetes and/or PAD according to European guidelines. ${ }^{28}{ }^{29}$ However, it is unknown whether supplementary antithrombotic medication would reduce amputation risk in diabetes patients with CAD. Sodium/glucose cotransporter (SGLT)-2 inhibitors and glucagon-like peptide (GLP)-1 analogs reduce cardiovascular risk and improve glycemic control in diabetes patients with atherosclerotic cardiovascular disease. ${ }^{30-35}$ However, SGLT-2 treatment have either had no impact or have been associated with an increased the risk of amputation. ${ }^{34}$ 36-38 Among the GLP-1 analogs, liraglutide reduces the risk of amputation semaglutide reduce the risk of lower limb revascularization, ${ }^{31}{ }^{37}$ while exanitide did not reduce amputation nor revascularization. ${ }^{39}$ Thus, class effects of GLP-1 analogs on lower limb revascularization and amputation is undetermined. None of the pivotal trials were powered to examine the effect of GLP-1 analogs on lower limb revascularization or amputation, and they only included diabetes patients with established atherosclerotic disease. The role of GLP-1 analogs in reducing amputation risk needs additional investigation in dedicated clinical trials, including examining their effect in diabetes patients without established cardiovascular disease.

\section{Limitations}

We did not have access to hemoglobin A1c in our dataset, and we cannot account for the effect of hyperglycemia in our study. However, we did find that amputation was associated with pseudoindicators of diabetes disease severity such as duration of diabetes and insulin treatment. The use of aspirin and statin was high in patients with $\mathrm{CAD}$, and this may have reduced the relative risk of symptomatic $\mathrm{PAD}$, lower limb intervention, and lower limb amputation. As such, we have likely underestimated the PAD 
risk among this subgroup. Our study included symptomatic patients undergoing CAG and may not represent the risk in the general population. Obstructive CAD was defined by $50 \%$ stenosis, which no longer reflects the current guidelines. However, in recent years Danish interventional cardiologists have increasingly been using intravascular pressure measurements, such as fractional flow ratio and adenosine-free resting indices, to identify functionally limiting lesions during CAG in accordance with guidelines. Lastly, PAD diagnosis were identified based on hospital and outpatient clinic diagnoses, likely underestimating the true prevalence of PAD.

\section{CONCLUSIONS}

Patients with diabetes had a higher risk of PAD, lower limb revascularization, and lower limb amputation despite the absence of CAD by CAG. Diabetes alone was associated with a higher risk of amputation than $\mathrm{CAD}$ alone. Furthermore, $\mathrm{CAD}$ was associated with risk of PAD, lower limb revascularization, and lower limb amputation among patients with diabetes, and the risks depend on the CAD extent, type of diabetes treatment, and the duration of diabetes. This emphasizes the need for continued monitoring and treatment of macrovascular and microvascular disease of all patients with diabetes, in particular, diabetes patients with documented CAD. Clinical trials are needed to examine whether newer glucose-lowering medications, such as SGLT-2 inhibitors and GLP-1 analogs, can effectively prevent lower limb amputations in patients with diabetes both with and without established coronary atherosclerosis.

Contributors KKWO and MM conceptualized and designed the study. KKWO performed data management, statistical analysis, and wrote first draft of the manuscript. CG, TT, RWT, and MM provided major revision of the manuscript. All authors read and approved the final manuscript.

Funding This work was supported by the Research Unit, Department of Cardiology, Aarhus University Hospital, Aarhus, Denmark.

Competing interests KKWO has received a speaking fee from Bayer. CG, TT, and RWT have nothing to declare. MM has received advisory board fees from Boehringer-Ingelheim, AstraZeneca, Novo Nordisk, BMS, Boston Scientific, and Bayer.

\section{Patient consent for publication Not required.}

Ethics approval The study was approved by a regional branch of the Danish Data Protection Agency (record no. 1-16-02-193-18). Registry-based studies do not require approval from ethics committees or informed consent from participants according to Danish regulation.

Provenance and peer review Not commissioned; externally peer reviewed.

Data availability statement No data are available. According to Danish data protection regulations, data cannot be made publicly available.

Supplemental material This content has been supplied by the author(s). It has not been vetted by BMJ Publishing Group Limited (BMJ) and may not have been peer-reviewed. Any opinions or recommendations discussed are solely those of the author(s) and are not endorsed by BMJ. BMJ disclaims all liability and responsibility arising from any reliance placed on the content. Where the content includes any translated material, BMJ does not warrant the accuracy and reliability of the translations (including but not limited to local regulations, clinical guidelines, terminology, drug names and drug dosages), and is not responsible for any error and/or omissions arising from translation and adaptation or otherwise.
Open access This is an open access article distributed in accordance with the Creative Commons Attribution Non Commercial (CC BY-NC 4.0) license, which permits others to distribute, remix, adapt, build upon this work non-commercially, and license their derivative works on different terms, provided the original work is properly cited, appropriate credit is given, any changes made indicated, and the use is non-commercial. See: http://creativecommons.org/licenses/by-nc/4.0/.

ORCID iD

Kevin Kris Warnakula Olesen http://orcid.org/0000-0002-0560-3615

\section{REFERENCES}

1 American Diabetes Association. 11. Microvascular Complications and Foot Care: Standards of Medical Care in Diabetes-2020. Diabetes Care 2020;43:S135-51.

2 American Diabetes Association. 10. Cardiovascular Disease and Risk Management: Standards of Medical Care in Diabetes-2020. Diabetes Care 2020;43:S111-34.

3 Beaney AJ, Nunney I, Gooday C, et al. Factors determining the risk of diabetes foot amputations--A retrospective analysis of a tertiary diabetes foot care service. Diabetes Res Clin Pract 2016;114:69-74.

4 Dalager S, Falk E, Kristensen IB, et al. Plaque in superficial femoral arteries indicates generalized atherosclerosis and vulnerability to coronary death: an autopsy study. J Vasc Surg 2008;47:296-302.

5 Olesen KKW, Madsen M, Egholm G, et al. Patients with diabetes without significant angiographic coronary artery disease have the same risk of myocardial infarction as patients without diabetes in a real-world population receiving appropriate prophylactic treatment. Diabetes Care 2017;40:1103-10.

6 Saely CH, Aczel S, Marte T, et al. Cardiovascular complications in type 2 diabetes mellitus depend on the coronary angiographic state rather than on the diabetic state. Diabetologia 2004;47:145-6.

7 Olesen KKW, Madsen M, Gyldenkerne C, et al. Diabetes mellitus is associated with increased risk of ischemic stroke in patients with and without coronary artery disease. Stroke 2019;50:3347-54.

8 Schmidt M, Pedersen L, Sørensen HT. The Danish civil registration system as a tool in epidemiology. Eur J Epidemiol 2014;29:541-9.

9 Pedersen CB. The Danish civil registration system. Scand J Public Health 2011;39:22-5.

10 Schmidt M, Schmidt SAJ, Sandegaard JL, et al. The Danish national patient registry: a review of content, data quality, and research potential. Clin Epidemiol 2015;7:449-90.

11 Pottegård A, Schmidt SAJ, Wallach-Kildemoes $\mathrm{H}$, et al. Data resource profile: the Danish national prescription registry. Int $J$ Epidemiol 2017;46:798-f.

12 Schmidt M, Maeng M, Madsen M, et al. The Western Denmark heart registry: its influence on cardiovascular patient care. J Am Coll Cardiol 2018;71:1259-72.

13 White IR, Royston P, Wood AM. Multiple imputation using chained equations: issues and guidance for practice. Stat Med 2011:30:377-99.

14 Van Buuren S. Flexible imputation of missing data. 2 ed. Boca Raton, FL, United States: CRC Press, 2012.

15 Olesen KKW, Riis AH, Nielsen LH, et al. Risk stratification by assessment of coronary artery disease using coronary computed tomography angiography in diabetes and non-diabetes patients: a study from the Western Denmark cardiac computed tomography registry. Eur Heart J Cardiovasc Imaging 2019;20:1271-8.

16 Afkarian M, Zelnick LR, Hall YN, et al. Clinical manifestations of kidney disease among US adults with diabetes, 1988-2014. JAMA 2016;316:602-10.

17 Yau JWY, Rogers SL, Kawasaki R, et al. Global prevalence and major risk factors of diabetic retinopathy. Diabetes Care 2012;35:556-64.

18 Jaiswal M, Divers J, Dabelea D, et al. Prevalence of and risk factors for diabetic peripheral neuropathy in youth with type 1 and type 2 diabetes: search for diabetes in youth study. Diabetes Care 2017;40:1226-32.

19 Beckman JA, Duncan MS, Damrauer SM, et al. Microvascular disease, peripheral artery disease, and amputation. Circulation 2019;140:449-58.

$20 \mathrm{Maeda} \mathrm{H}$, Sugiyama S, Jinnouchi H, et al. Advanced peripheral microvascular endothelial dysfunction and polyvascular disease in patients with high cardiovascular risk. J Cardiol 2016;67:455-62.

21 Taqueti VR, Di Carli MF. Coronary Microvascular Disease Pathogenic Mechanisms and Therapeutic Options: JACC State-of-the-Art Review. J Am Coll Cardiol 2018;72:2625-41.

22 American Diabetes Association. 11. Microvascular Complications and Foot Care: Standards of Medical Care in Diabetes-2019. Diabetes Care 2019;42:S124-38. 
23 Mohammedi K, Woodward M, Hirakawa Y, et al. Microvascular and macrovascular disease and risk for major peripheral arterial disease in patients with type 2 diabetes. Diabetes Care 2016;39:1796-803.

24 Kamil S, Sehested TSG, Carlson N, et al. Diabetes and risk of peripheral artery disease in patients undergoing first-time coronary angiography between 2000 and 2012 - a nationwide study. BMC Cardiovasc Disord 2019;19:234.

25 Gerhard-Herman MD, Gornik HL, Barrett C. 2016 AHAVACC guideline on the management of patients with lower extremity peripheral artery disease. A Report of the American College of Cardiology/American Heart Association Task Force on Clinical Practice Guidelines 2017;69:e71-126.

26 Eikelboom JW, Connolly SJ, Bosch J, et al. Rivaroxaban with or without aspirin in stable cardiovascular disease. N Engl J Med 2017;377:1319-30.

27 Anand SS, Bosch J, Eikelboom JW, et al. Rivaroxaban with or without aspirin in patients with stable peripheral or carotid artery disease: an international, randomised, double-blind, placebocontrolled trial. The Lancet 2018;391:219-29.

28 Anand SS, Eikelboom JW, Dyal L, et al. Rivaroxaban plus aspirin versus aspirin in relation to vascular risk in the COMPASS trial. J Am Coll Cardiol 2019;73:3271-80.

29 Knuuti J, Wijns W, Saraste A. 2019 ESC guidelines for the diagnosis and management of chronic coronary syndromes: the task force for the diagnosis and management of chronic coronary syndromes of the European Society of cardiology (ESC). Eur Heart $J$ 2019;41:407-77.

30 Zinman B, Wanner C, Lachin JM, et al. Empagliflozin, cardiovascular outcomes, and mortality in type 2 diabetes. N Engl J Med 2015;373:2117-28.
31 Marso SP, Bain SC, Consoli A, et al. Semaglutide and cardiovascular outcomes in patients with type 2 diabetes. $N$ Engl $\mathrm{J}$ Med 2016;375:1834-44.

32 Marso SP, Daniels GH, Brown-Frandsen K, et al. Liraglutide and cardiovascular outcomes in type 2 diabetes. $N$ Engl J Med 2016;375:311-22.

33 Neal B, Perkovic V, Mahaffey KW, et al. Canagliflozin and cardiovascular and renal events in type 2 diabetes. $N$ Engl J Med 2017;377:644-57.

34 Wiviott SD, Raz I, Bonaca MP, et al. Dapagliflozin and cardiovascular outcomes in type 2 diabetes. N Engl J Med 2019;380:347-57.

35 Zelniker TA, Wiviott SD, Raz I, et al. Sglt2 inhibitors for primary and secondary prevention of cardiovascular and renal outcomes in type 2 diabetes: a systematic review and meta-analysis of cardiovascular outcome trials. Lancet 2019;393:31-9.

36 Inzucchi SE, Iliev H, Pfarr E, et al. Empagliflozin and assessment of lower-limb amputations in the EMPA-REG outcome trial. Diabetes Care 2018;41:e4-5.

37 Dhatariya K, Bain SC, Buse JB, et al. The impact of liraglutide on diabetes-related foot ulceration and associated complications in patients with type 2 diabetes at high risk for cardiovascular events: results from the leader trial. Diabetes Care 2018;41:2229-35.

38 Matthews DR, Li Q, Perkovic V, et al. Effects of canagliflozin on amputation risk in type 2 diabetes: the canvas program. Diabetologia 2019;62:926-38.

39 Badjatiya A, Merrill P, Buse JB, et al. Clinical outcomes in patients with type 2 diabetes mellitus and peripheral artery disease: results from the EXSCEL trial. Circ Cardiovasc Interv 2019;12:e008018. 